\title{
Cardiovascular diseases and risk factors in kidney transplant candidates
}

\author{
Umut Kocabaş®
}

Department of Cardiology, Başkent University İzmir Hospital, İzmir, Turkey

\begin{abstract}
Objectives: Cardiovascular diseases and risk factors are associated with adverse cardiac events following kidney transplant. Therefore, pre-transplant evaluation of cardiovascular diseases and risk factors is important for determining the cardiac risk. The objective of this study is to determine the prevalence of cardiovascular diseases and risk factors in kidney transplant candidates.

Methods: This is a single-center and observational study which includes 174 end-stage renal disease patients (male: $55.2 \%$ and mean age: $49 \pm 13$ years) who underwent kidney transplant. Preoperative clinical characteristics, cardiovascular diseases and risk factors of the patients were examined retrospectively.

Results: The study population had multiple cardiovascular risk factors such as hypertension (66.7\%), diabetes $(28.2 \%)$, dyslipidemia $(29.9 \%)$ and smoking $(30.5 \%)$ in the evaluation conducted prior to kidney transplant. The most common cardiovascular diseases were detected as congestive heart failure $(10.9 \%)$ and coronary artery disease $(8.6 \%)$. The rate of the patients who underwent myocardial revascularization (percutaneous coronary intervention or coronary artery bypass grafting) before kidney transplant was $6.9 \%$. The patients' mean left ventricular mass index was $114 \pm 32 \mathrm{~g} / \mathrm{m} 2$, and $55.5 \%$ of the study population had left ventricular hypertrophy.
\end{abstract}

Conclusions: In our study, the prevalence of cardiovascular diseases and risk factors in the patients who underwent kidney transplant was found to be high.

Keywords: cardiovascular disease, kidney transplantation, risk factor

$\mathrm{C}$ ardiovascular diseases and cardiovascular risk factors such as hypertension, diabetes mellitus, dyslipidemia, smoking, left ventricular hypertrophy are commonly seen in patients with end-stage renal disease (ESRD) [1,2]. The prevalence of coronary artery disease in ESRD patients who received chronic dialysis was found to be $40 \%$, while the prevalence of left ventricular hypertrophy was detected as $75 \%$, and it is known that the risk of cardiovascular morbidity and mortality has considerably increased in these patients [3]. Kidney transplant is the most appropriate treatment strategy for patients with ESRD, and it is as- sociated with lower cardiovascular mortality rates compared to chronic dialysis therapy [4]. Moreover, cardiovascular diseases are more commonly seen in patients who undergo kidney transplant compared to the general population and continue to be the leading cause of post-transplant mortality and morbidity [5].

Current guidelines recommend a detailed pre-operative cardiovascular evaluation and assessment of the patient's individual risk status in ESRD patients who will undergo kidney transplant $[6,7]$. In these patients, evaluation, treatment and control of cardiovascular diseases and risk factors are very important in 
terms of preventing undesired post-transplant cardiac events [8]. However, in Turkish population, information regarding the frequency of cardiovascular diseases and risk factors in ESRD patients who will undergo kidney transplant is limited.

The objective of this study is to determine the frequency of cardiovascular diseases and cardiovascular risk factors in ESRD patients who will undergo kidney transplant.

\section{METHODS}

The present study was conducted in accordance with the principles of the Declaration of Helsinki. The study was approved by Baskent University Institutional Review Board (Project no: 94603339-604.01.02/9412 KA20/100) on 10/03/2020.

\section{Study Population}

One hundred seventy-four ESRD patients, who underwent kidney transplantation at Başkent University Istanbul Health Practice and Research Center Hospital between January 2011 and January 2017, were included in this study. The patients with ESRD under 18 years of age and the patients whose reliable medical archive records could not be reached were not included in the study.

The patients' demographic characteristics, etiologies of chronic renal failure, type and duration of the dialysis treatment applied, cardiovascular diseases and cardiovascular risk factors, medical treatments they received and laboratory analyses obtained during the cardiological examination performed before the transplant, electrocardiographic and echocardiographic characteristics were retrospectively obtained from hospital's medical records.

\section{Definitions}

In the pre-transplant evaluation, hypertension was defined as the detection of systolic blood pressure as $\geq 140 \mathrm{mmHg}$ and/or diastolic blood pressure as $\geq 90$ $\mathrm{mmHg}$ in the consecutive two blood pressure measurements. The patients, who were previously diagnosed with hypertension and/or used antihypertensive drugs, were accepted as hypertensive patients regardless of the value of the measured blood pressure [9]. Diabetes mellitus was accepted as the detection of fasting plasma glucose as $\geq 126 \mathrm{mg} / \mathrm{dL}$ or $\mathrm{HbA} 1 \mathrm{c}$ value as $\geq 6.5 \%$ in the blood glucose measurement. The patients with a previous diagnosis of diabetes mellitus and/or using antidiabetic medication or insulin therapy were accepted as diabetic patients regardless of their blood glucose and HbAlc values [10]. Hyperlipidemia was accepted as the detection of low-density lipoprotein value as $130 \mathrm{mg} / \mathrm{dL}$ or total cholesterol value as $\geq 200 \mathrm{mg} / \mathrm{dL}$ or triglyceride value as $\geq 150$ $\mathrm{mg} / \mathrm{dL}$ in blood lipids measurement. The patients, who were previously diagnosed with hyperlipidemia and/or received lipid-lowering medication were accepted as hyperlipidemic patients regardless of their measured lipid values [11]. Occlusive coronary artery disease was defined as the detection of $\geq 50 \%$ stenosis in the left main coronary artery and/or $\geq 70 \%$ stenosis in the left anterior descending and/or circumflex and/or right coronary arteries in coronary angiography and/or the

\section{Cardiovascular risk factors}

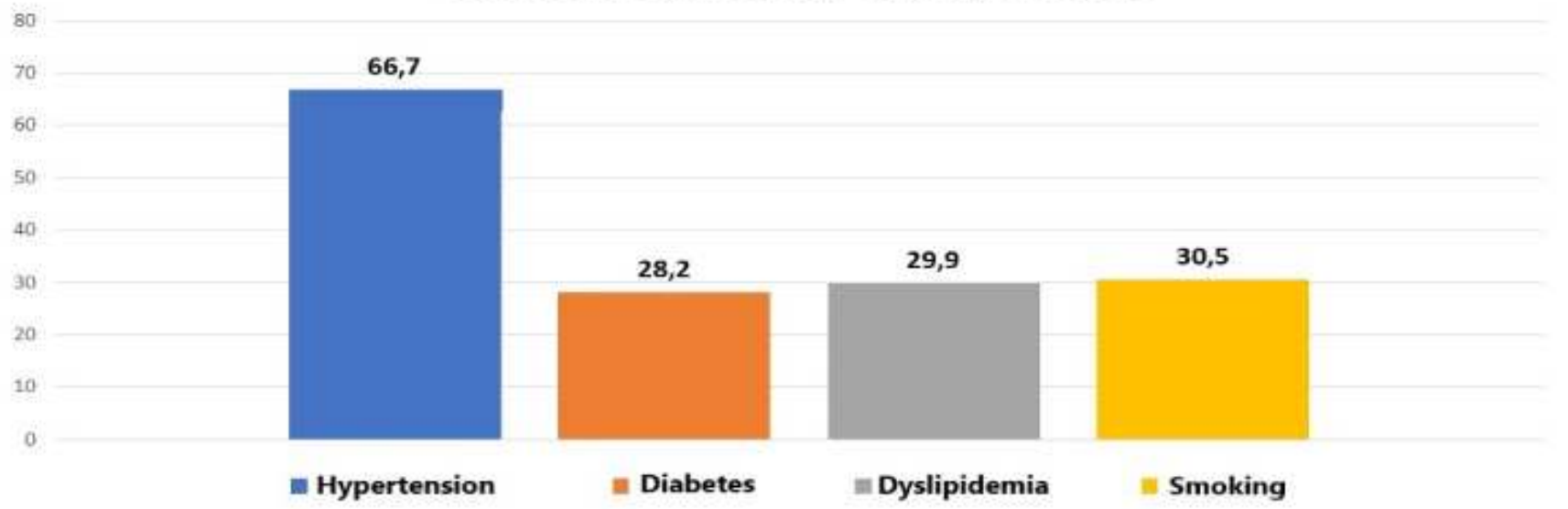

Fig. 1. The figure shows the prevalence distribution of cardiovascular risk factors in the study population. 
application of coronary revascularization [12]. Congestive heart failure was defined as the detection of left ventricular ejection fraction as $<50 \%$ together with heart failure symptoms and findings or the detection of natriuretic peptide elevation and/or left ventricular hypertrophy and/or left atrial dilatation and/or left ventricular diastolic dysfunction in the patients with heart failure symptoms and findings and left ventricular ejection fraction as $\geq 50 \%$ [13]. Left ventricular mass index was calculated by using the Devereux formula in the light of the echocardiographic data obtained [14]. Left ventricular hypertrophy was defined as the detection of left ventricular mass index as $>95$ $\mathrm{g} / \mathrm{m}^{2}$ in female patients and $>115 \mathrm{~g} / \mathrm{m} 2$ in male patients.

\section{Statistical Analysis}

Statistical analyses of the study were performed by using the SPSS software package (SPSS, Inc., Chicago, IL, USA) version 22.0. Continuous variables were expressed as mean \pm standard deviation (mean \pm $\mathrm{SD}$ ) or median and range, while categorical variables were presented as frequency and percentage $(\%)$.

\section{RESULTS}

The mean age of 174 patients included in the study was $49.2 \pm 13.0$ years, while 96 patients $(55.2 \%)$ were male. The demographic and clinical characteristics of the patients are shown in Table 1. One hundred fortyfive $(83.3 \%)$ ESRD patients were receiving dialysis treatment. The median dialysis treatment duration before kidney transplant was 24 months. Ten patients $(5.7 \%)$ had previously undergone kidney transplant. When it was evaluated in terms of ESRD etiology, the most common causes were hypertensive nephropathy $(32.2 \%)$, diabetic nephropathy $(18.4 \%)$, glomerulonephritis (17.8\%) and polycystic kidney disease $(9.2 \%)$. The etiology of renal failure was not detected in $18.4 \%$ of the patients.

The most common cardiovascular risk factors were hypertension (66.7\%), smoking (30.5\%), hyperlipidemia (29.9\%) and diabetes mellitus (28.2\%) (Fig. $1)$. The most common accompanying cardiovascular diseases in the patients with ESRD were congestive heart failure $(10.9 \%)$ and obstructive coronary artery disease $(8.6 \%)$. Only 2 patients had a history of atrial fibrillation, and 1 patient had a history of cerebrovascular disease (Fig. 2). The most common non-cardiac comorbidities were anemia (76.4\%), hyperthyroidism or hypothyroidism $(9.8 \%)$, major depression $(9.8 \%)$ and chronic obstructive pulmonary disease $(3.4 \%)$ (Table 1).

Before kidney transplant, $47.7 \%$ of the patients were using dihydropyridine group calcium channel blocker, $33.3 \%$ beta adrenergic receptor blocker, $26.4 \%$ antiaggregant treatment, $14.9 \%$ diuretic treatment, 14.4\% renin angiotensin system blocker, 14.4\% alpha adrenergic receptor blocker and $12.6 \%$ statin treatment (Table 2).

In the pre-transplant evaluation of the ESRD patients included in the study, the median serum creatinine value was detected as $7.0 \mathrm{mg} / \mathrm{dL}$ (range: $2.1-16.0$

\section{Cardiovascular diseases}

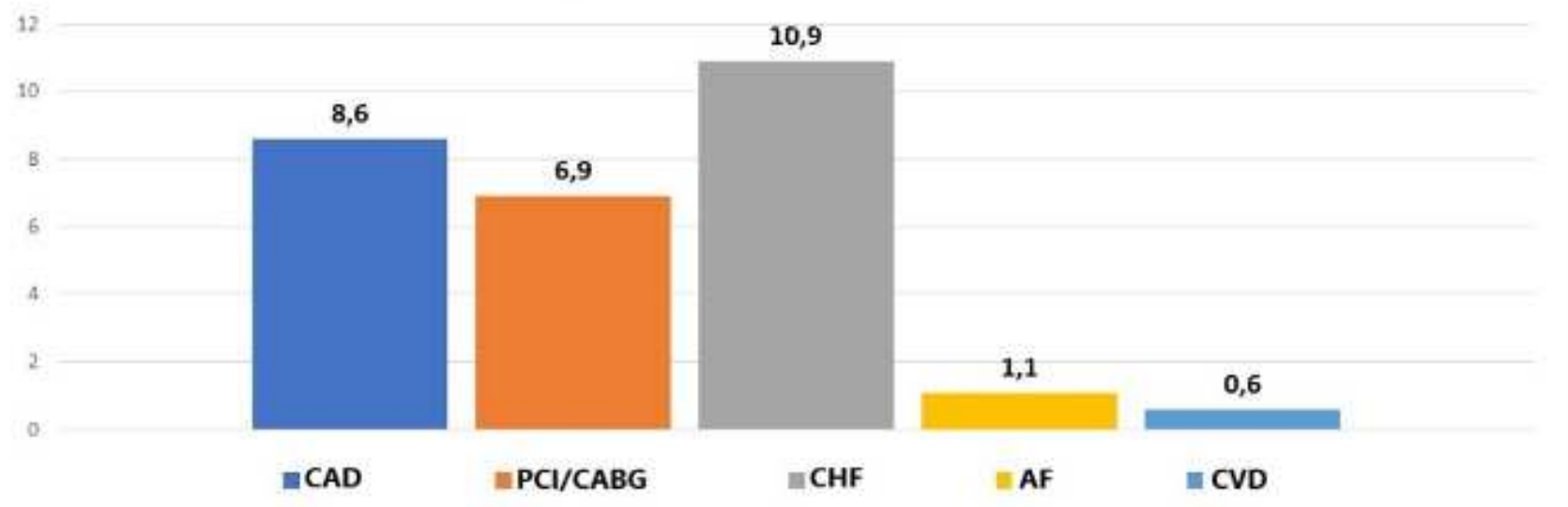

Fig. 2. The figure shows the prevalence distribution of cardiovascular diseases in the study population. (CAD = coronary artery disease, $\mathrm{PCI}=$ percutaneous coronary intervention, $\mathrm{CABG}=$ coronary artery bypass grafting, $\mathrm{CHF}=\mathrm{congestive} \mathrm{heart}$ failure, $\mathrm{AF}=$ atrial fibrillation, $\mathrm{CVD}=$ cerebrovascular disease). 
Table 1. Clinical characteristics of kidney transplant candidates

\begin{tabular}{|c|c|}
\hline Variables & $\mathrm{n}=174$ \\
\hline Age, years & $49.2 \pm 13.0$ \\
\hline Sex, male & $96(55.2)$ \\
\hline Dialysis treatment before kidney transplant & $145(83.3)$ \\
\hline \multicolumn{2}{|l|}{ Dialysis type } \\
\hline Hemodialysis & $126(72.4)$ \\
\hline Peritoneal dialysis & $19(10.9)$ \\
\hline Dialysis treatment duration before kidney transplant (months) & $24(1-240)$ \\
\hline History of kidney transplantation & $10(5.7)$ \\
\hline \multicolumn{2}{|l|}{ Donor type } \\
\hline Living donor & $147(84.5)$ \\
\hline Deceased donor & $27(15.5)$ \\
\hline \multicolumn{2}{|l|}{ End-stage renal disease etiology } \\
\hline Hypertensive nephropathy & $56(32.2)$ \\
\hline Diabetic nephropathy & $32(18.4)$ \\
\hline Glomerulonephritis & $31(17.8)$ \\
\hline Polycystic kidney disease & $16(9.2)$ \\
\hline Connective tissue disease & $4(2.3)$ \\
\hline Renovascular disease & $3(1.7)$ \\
\hline Unknown & $32(18.4)$ \\
\hline \multicolumn{2}{|l|}{ Cardiovascular risk factors } \\
\hline Hypertension & $116(66.7)$ \\
\hline Diabetes mellitus & $49(28.2)$ \\
\hline Dyslipidemia & $52(29.9)$ \\
\hline Smoking & $53(30.5)$ \\
\hline Cardiovascular diseases & $22(12.6)$ \\
\hline Obstructive coronary artery disease & $15(8.6)$ \\
\hline History of myocardial revascularization & $12(6.9)$ \\
\hline Heart failure & $19(10.9)$ \\
\hline Atrial fibrillation & $2(1.1)$ \\
\hline Cerebrovascular disease & $1(0.6)$ \\
\hline \multicolumn{2}{|l|}{ Other chronic conditions } \\
\hline Chronic obstructive pulmonary disease & $6(3.4)$ \\
\hline Anemia & $133(76.4)$ \\
\hline Thyroid disease & $17(9.8)$ \\
\hline Depression & $17(9.8)$ \\
\hline
\end{tabular}

Data are given as mean $\pm \mathrm{SD}$ or $\mathrm{n}(\%)$. 
Tablo 2. Medical treatments, laboratory results, electrocardiographic and echocardiographic data of kidney transplant candidates

\begin{tabular}{|c|c|}
\hline Variables & $\mathrm{n}=174$ \\
\hline \multicolumn{2}{|l|}{ Medical treatments } \\
\hline Renin angiotensin system inhibitors & $25(14.4)$ \\
\hline Beta - blockers & $58(33.3)$ \\
\hline Diuretics & $26(14.9)$ \\
\hline Calcium channel blockers & $83(47.7)$ \\
\hline Alpha blockers & $25(14.4)$ \\
\hline Statins & $22(12.6)$ \\
\hline Antiaggregant/anticoagulants & $46(26.4)$ \\
\hline \multicolumn{2}{|l|}{ Laboratory data } \\
\hline Serum creatinine $(\mathrm{mg} / \mathrm{dL})$ & $7.0(2.1-16.0)$ \\
\hline Fasting blood glucose (mg/dL) & $102(76-552)$ \\
\hline $\mathrm{HbA1c}(\%)$ & $5.2(3.5-9.6)$ \\
\hline Low-density lipoprotein cholesterol (mg/dL) & $111 \pm 40$ \\
\hline Hematocrit (\%) & $30.8 \pm 5.4$ \\
\hline C-reactive protein $(\mathrm{mg} / \mathrm{dL})$ & $4.0(0.2-98)$ \\
\hline Thyroid stimulating hormone (mU/L) & $1.5(0.006-8.5)$ \\
\hline Parathyroid hormone (pg/dL) & $264(17-2071)$ \\
\hline \multicolumn{2}{|l|}{ Electrocardiographic data (117 patients) } \\
\hline Sinus rhythm & $115 / 117(98.3)$ \\
\hline Heart rate (bpm) & $79 \pm 13$ \\
\hline Left bundle branch block & 2/117 (1.7) \\
\hline Non-Left Bundle Branch Block & 4/117 (3.4) \\
\hline \multicolumn{2}{|l|}{ Echocardiographic data (164 patients) } \\
\hline Left ventricular ejection fraction (\%) & $58 \pm 4$ \\
\hline Left atrial diameter (mm) & $38 \pm 6$ \\
\hline Mitral E velocity $(\mathrm{cm} / \mathrm{s})$ & $79 \pm 24$ \\
\hline Mitral A velocity $(\mathrm{cm} / \mathrm{s})$ & $76 \pm 22$ \\
\hline $\mathrm{E} / \mathrm{A}$ ratio & $1.1 \pm 0.4$ \\
\hline Posterior wall thickness (mm) & $11.9 \pm 1.7$ \\
\hline Interventricular septum thickness (mm) & $12.1 \pm 1.8$ \\
\hline Left ventricular hypertrophy & $91 / 164(55.5)$ \\
\hline Left ventricular mass index $(\mathrm{g} / \mathrm{m} 2)$ & $114 \pm 32$ \\
\hline Moderate-to-severe mitral regurgitation & $25 / 164(15.2)$ \\
\hline Moderate-to-severe tricuspid regurgitation & $16 / 164(9.8)$ \\
\hline Systolic pulmonary artery pressure (mm Hg) & $40(25-65)$ \\
\hline
\end{tabular}

Data are given as mean $\pm \mathrm{SD}$ or $\mathrm{n}(\%)$. 
$\mathrm{mg} / \mathrm{dL}$ ), the median fasting glucose $102 \mathrm{mg} / \mathrm{dL}$ (range: 76-552) and the median HbA1c value 5.2\% (range: $3.5 \%-9.6 \%$ ). The mean low-density lipoprotein value of the patient population was $111 \pm 40 \mathrm{mg} / \mathrm{dL}$, and the mean hematocrit value was $30.8 \% \pm 5.4 \%$ (Table 2 ).

Prior to the transplant, electrocardiographic evaluation data were obtained in 117 of 174 patients included in the study. It was observed that $98.3 \%$ of these patients were had normal sinus rhythm, and their mean heart rate was $79 \pm 13$ beats/minute. Only 2 patients $(1.7 \%)$ had left bundle branch block and 4 patients $(3.4 \%)$ had right bundle branch block or intraventricular conduction disturbance. Transthoracic echocardiographic examination was performed in 164 of 174 patients before kidney transplant. The mean left ventricular ejection fraction of the patient population was $58 \% \pm 4 \%$, while the mean left atrium diameter was $38 \pm 6 \mathrm{~mm}$. The mean left ventricular mass index was found as $114 \pm 32 \mathrm{~g} / \mathrm{m} 2$, and the left ventricular hypertrophy was detected in 91 patients $(55.5 \%)$. Moderate and/or severe mitral insufficiency was observed in $15.2 \%$ of the patients who underwent echocardiographic examination, and moderate and/or severe tricuspid insufficiency was observed in $9.8 \%$ of the patients. The median systolic pulmonary artery pressure of the patients was found as $40 \mathrm{mmHg}$ (range: 25-65 mmHg) (Table 2).

\section{DISCUSSION}

In the present study, the prevalence of accompanying cardiovascular diseases and cardiovascular risk factors as well as medications, laboratory data, electrocardiographic and echocardiographic characteristics of the patients with ESRD, who underwent kidney transplant, were determined.

The age of kidney transplant in patients with ESRD varies between $43-50$ years, and $58 \%-61 \%$ of these patients consist of male patients [15-19]. The age of the patients included in our study was found as 49 years in accordance with the literature, and $55 \%$ of them were male.

In the patients undergoing kidney transplant, longterm dialysis treatment before transplant and transplant from cadaver were found to be associated with an increased incidence of adverse cardiovascular events in the post-transplant period [20,21]. Previous studies reveal that the duration of dialysis treatment in the pre-transplant period varies between 18 months and 36 months on average $[15,16,22,23]$. In our study, the mean dialysis treatment duration before transplant was determined to be 24 months similar to the previous studies. One of the most important differences of our study compared to the literature is the donor-type distribution. Literature data reveal that kidney transplant in patients with ESRD is mostly performed from cadavers rather than living donors. This rate varies between $83 \%$ and $92 \%[15,16]$. In our study, differently from the literature, it was found that only $15.5 \%$ of the patients underwent kidney transplant from a cadaver, and $84.5 \%$ of the patients underwent kidney transplant from a living donor. This situation reveals the inadequacy of organ donation in Turkey and shows that studies that will be conducted countrywide are needed to popularize organ donation.

Our results put forward that the most common cardiovascular risk factor in patients with ESRD who undergo kidney transplant is hypertension. In our study, the prevalence of hypertension was found as $66.7 \%$. While the prevalence of hypertension is between $21 \%$ and $26 \%$ in the general population, this rate varies between $67 \%$ and $86 \%$ in patients with ESRD. This is similar to our study data $[16,18,19,24]$.

The prevalence of diabetes mellitus in patients undergoing kidney transplant varies widely from study to study. The study conducted by Fazelzadeh et al. evaluated 500 patients who underwent kidney transplant and found the prevalence of diabetes as 7\% [18]. On the other hand, in a comprehensive study conducted by Goyal et al. [17] where they evaluated 147,431 patients who underwent kidney transplant, the prevalence of diabetes was found to be $24 \%$. The prevalence of diabetes mellitus in our study was $28.2 \%$, and it was higher than other studies where kidney transplant candidates were evaluated [17-19, 24, $25]$. According to the assessment results of the European Society of Cardiology 2019 Cardiovascular Diseases Statistics [26], the median prevalence of diabetes mellitus in the general population in the 20-79 age group was $6.8 \%$; this rate was found to be $12.1 \%$ in Turkey. Our country is the third country with the highest prevalence of diabetes after Egypt and Lebanon. Similarly, in Turkey, the prevalence of obesity (body mass index $\geq 30 \mathrm{~kg} / \mathrm{m} 2$ ) was reported as $25 \%$ in males and $39 \%$ in females. The high prevalence of diabetes 
in our study population may be a result of the increased prevalence of obesity and diabetes in the general population.

The presence of accompanying cardiovascular disease in patients with ESRD is one of the strongest predictors of adverse cardiovascular events in the post-transplant period. According to the results of a study conducted by Aalten et al. [15] where 2187 patients, who underwent kidney transplant, were evaluated, the presence of cardiovascular disease before transplant increased the risk of undesired cardiovascular events in the post-transplant period by $76 \%$. This result was confirmed by other observational studies evaluating kidney transplant patients $[16,22]$. The study results show that the prevalence of cardiovascular disease varies between $7 \%$ and $16 \%$ in ESRD patients undergoing kidney transplant $[15,16,22]$. In our study, it was found that $8.6 \%$ of the patients had obstructive coronary artery disease, and $10.9 \%$ had congestive heart failure, in accordance with the current data.

In this patient group, another important cardiovascular risk factor is smoking. Studies reveal that active smoking or the history of smoking is associated with the development of cardiovascular complications in the post-transplant period [19, 22, 23]. Gonçalves et al. [19] reported that the 7-year all-cause mortality risk was higher than $10 \%$ in kidney transplant individuals who were smoking actively or who smoked in the past. Similarly, Chuang et al. [23] found that pre-transplant smoking increased the risk of developing acute coronary syndrome 3.5 times more in the early period of the first 2 years after the transplantation. In studies involving kidney transplant patients, the smoking rate was quite high and ranged from $25 \%$ to $50 \%[16,19$, $22]$. In our country, the prevalence of smoking in the general population aged 15 years and above varies between $40-45 \%$ in males and $10-15 \%$ in females [26]. Our study shows that approximately one third of the patients who undergo kidney transplant actively smoke or have a history of smoking. In our study, the prevalence of smoking was found to be $30.5 \%$ among patients, and this rate almost coincides with the rates in the general population. This situation shows that the efforts and campaigns across the country to provide support for smoking cessation are still insufficient. More widespread and aggressive strategies are needed across the country in order to achieve a reduction in terms of smoking.

The presence of left ventricular hypertrophy is a risk factor for the development of cardiovascular diseases [9]. The presence of left ventricular hypertrophy in the patients with ESRD is associated with the development of ischemic heart disease, congestive heart failure and ventricular arrhythmia [27]. The prevalence of left ventricular hypertrophy in patients undergoing kidney transplant ranges from $45 \%$ to $75 \%$. This significant difference revealed in different studies is due to the lack of a standard approach in the diagnostic methods and estimation values used to detect left ventricular hypertrophy. In our study, the prevalence of left ventricular hypertrophy was found as $55.5 \%$.

\section{Limitations}

The most important limitations of our study are its retrospective design and the inclusion of the patients from a single center. The relatively limited number of the patients included in the study reduces the statistical power of the study. Retrospective data were based on the documentation of medical history, clinical examination and treatments during the preoperative cardiac examination, and follow-up data after renal transplantation were not obtained. Thus, the rehospitalization and mortality rates of the patients after transplantation are unknown. Because of these limitations, the results of this study should be interpreted carefully.

\section{CONCLUSION}

Our study reveals that the prevalence of cardiovascular disease and cardiovascular risk factors is high in ESRD patients undergoing kidney transplant. Therefore, pre-operative cardiovascular risk assessment is important in terms of minimizing the risk of adverse events in the post-transplant period in ESRD patients who are kidney transplant candidates.

\section{Authors' Contribution}

Study Conception: UK; Study Design: UK; Supervision: UK; Funding: UK; Materials: UK; Data Collection and/or Processing: UK; Statistical Analysis and/or Data Interpretation: UK; Literature Review: UK; Manuscript Preparation: UK and Critical Review: UK. 


\section{Conflict of interest}

The authors disclosed no conflict of interest during the preparation or publication of this manuscript.

\section{Financing}

The authors disclosed that they did not receive any grant during conduction or writing of this study.

\section{REFERENCES}

1. Jardine A, Gaston R, Fellstrom B, Holdaas H. Prevention of cardiovascular disease in adult recipients of kidney transplants. Lancet 2011;378:1419-27.

2. Soveri I, Holme I, Holdaas H, Budde K, Jardine AG, Fellström B. A cardiovascular risk calculator for renal transplant recipients. Transplantation 2012;94:57-62.

3. Foley RN, Parfrey PS, Sarnak MJ. Clinical epidemiology of cardiovascular disease in chronic renal disease. Am J Kidney Dis 1998;32:S112-9.

4. Wolfe RA, Ashby VB, Milford EL, Ojo AO, Ettenger RE, Agodoa LY, et al. Comparison of mortality in all patients on dialysis, patients on dialysis awaiting transplantation, and recipients of a first cadaveric transplant. N Engl J Med 1999;341:1725-30. 5. Pilmore H, Dent H, Chang S, McDonald SP, Chadban SJ. Reduction in cardiovascular death after kidney transplantation. Transplantation 2010;89:851-7.

6. Lentine KL, Costa SP, Weir MR, Robb JF, Fleisher LA, Kasiske BL, et al.; Cardiac disease evaluation and management among kidney and liver transplantation candidates: a scientific statement from the American Heart Association and the American College of Cardiology Foundation: endorsed by the American Society of Transplant Surgeons, American Society of Transplantation, and National Kidney Foundation. Circulation 2012;126:617-63.

7. Kasiske BL, Zeier MG, Chapman JR, Craig JC, Ekberg H, Garvey CA, et al; Kidney Disease: Improving Global Outcomes. KDIGO clinical practice guideline for the care of kidney transplant recipients: a summary. Kidney Int 2010;77:299-311.

8. Aalten J, Hoogeveen EK, Roodnat JI, Weimar W, Borm GF, de Fijter JW, et al. Associations between pre-kidney-transplant risk factors and post-transplant cardiovascular events and death. Transpl Int 2008;21:985-91.

9. Mancia G, Fagard R, Narkiewicz K, Redon J, Zanchetti A, Böhm M, et al. $2013 \mathrm{ESH} / \mathrm{ESC}$ guidelines for the management of arterial hypertension: the Task Force for the Management of Arterial Hypertension of the European Society of Hypertension (ESH) and of the European Society of Cardiology (ESC). Eur Heart J 2013;34:2159-219.

10. Cosentino F, Grant PJ, Aboyans V, Bailey CJ, Ceriello A, Delgado V, et al.; ESC Scientific Document Group. 2019 ESC Guidelines on diabetes, pre-diabetes, and cardiovascular diseases developed in collaboration with the EASD. Eur Heart J 2020;41:255-323.

11. Mach F, Baigent C, Catapano AL, Koskinas KC, Casula M,
Badimon L, et al.; ESC Scientific Document Group. 2019 ESC/EAS Guidelines for the management of dyslipidaemias: lipid modification to reduce cardiovascular risk. Eur Heart J 2020;41:111-88.

12. Knuuti J, Wijns W, Saraste A, Capodanno D, Barbato E, Funck-Brentano C, et al.; ESC Scientific Document Group. 2019 ESC Guidelines for the diagnosis and management of chronic coronary syndromes. Eur Heart J 2020;41:407-77.

13. Ponikowski P, Voors AA, Anker SD, Bueno H, Cleland JGF, Coats AJS, et al.; ESC Scientific Document Group. 2016 ESC Guidelines for the diagnosis and treatment of acute and chronic heart failure: The Task Force for the diagnosis and treatment of acute and chronic heart failure of the European Society of Cardiology (ESC)Developed with the special contribution of the Heart Failure Association (HFA) of the ESC. Eur Heart J 2016;37:2129200.

14. Devereux RB, Alonso DR, Lutas EM, Gottlieb GJ, Campo E, Sachs I, et al. Echocardiographic assessment of left ventricular hypertrophy: comparison to necropsy findings. Am J Cardiol 1986;57:450-8.

15. Aalten J, Hoogeveen EK, Roodnat JI, Weimar W, Borm GF, de Fijter JW, et al. Associations between pre-kidney-transplant risk factors and post-transplant cardiovascular events and death. Transpl Int 2008;21:985-91.

16. Vanrenterghem YF, Claes K, Montagnino G, Fieuws S, Maes B, Villa M, et al. Risk factors for cardiovascular events after successful renal transplantation. Transplantation 2008;85:209-16.

17. Goyal A, Chatterjee K, Mathew RO, Sidhu MS, Bangalore S, McCullough PA, et al. In-Hospital Mortality and Major Adverse Cardiovascular Events after Kidney Transplantation in the United States. Cardiorenal Med 2019;9:51-60.

18. Fazelzadeh A, Mehdizadeh A, Ostovan MA, Raiss-Jalali GA. Incidence of cardiovascular risk factors and complications before and after kidney transplantation. Transplant Proc 2006;38:5068.

19. Gonçalves M, Vieira P, Resende L, Durães J, Rosa N, Teixeira JA, et al. Metabolic profile and cardiovascular risk in a population of renal transplant recipients. Transplant Proc 2015;47:9858.

20. Rigatto C, Parfrey P, Foley R, Negrijn C, Tribula C, Jeffery $\mathrm{J}$. Congestive heart failure in renal transplant recipients: risk factors, outcomes, and relationship with ischemic heart disease. J Am Soc Nephrol 2002;13:1084-90.

21. Abbott KC, Bucci JR, Cruess D, Taylor AJ, Agodoa LY. Graft loss and acute coronary syndromes after renal transplantation in the United States. J Am Soc Nephrol 2002;13:2560-9.

22. Seoane-Pillado MT, Pita-Fernández S, Valdés-Cañedo F, Seijo-Bestilleiro R, Pértega-Díaz S, Fernández-Rivera C, et al. Incidence of cardiovascular events and associated risk factors in kidney transplant patients: a competing risks survival analysis. BMC Cardiovasc Disord 2017; 17:72.

23. Chuang P, Gibney EM, Chan L, Ho PM, Parikh CR. Predictors of cardiovascular events and associated mortality within two years of kidney transplantation. Transplant Proc 2004;36:138791.

24. Díaz JM, Gich I, Bonfill X, Solà R, Guirado L, Facundo C, et al. Prevalence evolution and impact of cardiovascular risk fac- 
tors on allograft and renal transplant patient survival. Transplant Proc 2009;41:2151-5.

25. Ojo AO. Cardiovascular complications after renal transplantation and their prevention. Transplantation 2006;82:603-11. 26. Timmis A, Townsend N, Gale CP, Torbica A, Lettino M, Petersen SE, et al.; European Society of Cardiology. European So- ciety of Cardiology: Cardiovascular Disease Statistics 2019. Eur Heart J 2020;41:12-85.

27. Noshad H, Ardalan MR, Mortazavi M, Tayebi H, Safa J, Nezami N. Kidney transplantation candidates and cardiovascular risk factors. Transplant Proc 2007;39:871-4. 